\title{
Dual Inhibition of Endocannabinoid Catabolic Enzymes Produces Enhanced Antiwithdrawal Effects in Morphine-Dependent Mice
}

\author{
Divya Ramesh', Thomas F Gamage', Tim Vanuytsel ${ }^{2,3}$, Robert A Owens', Rehab A Abdullah', \\ Micah J Niphakis ${ }^{4}$, Terez Shea-Donohue ${ }^{3}$, Benjamin F Cravatt ${ }^{4}$ and Aron H Lichtman ${ }^{*, 1,5}$ \\ 'Department of Pharmacology and Toxicology, Medical College of Virginia Campus, Virginia Commonwealth University, Richmond, VA, USA; \\ ${ }^{2}$ Translational Research Center for Gastrointestinal Disorders (TARGID), Katholieke Universiteit Leuven, Leuven, Belgium; ${ }^{3}$ Mucosal Biology \\ Research Center, University of Maryland, Baltimore (MD), Baltimore, MD, USA; ${ }^{4}$ Department of Chemical Physiology and the Skaggs Institute for \\ Structural Biology, The Scripps Research Institute, La Jolla, CA, USA; ${ }^{5}$ Institute for Drug and Alcohol Studies, Virginia Commonwealth University, \\ Richmond, VA, USA
}

\begin{abstract}
Inhibition of the endocannabinoid catabolic enzymes, monoacylglycerol lipase (MAGL) or fatty acid amide hydrolase (FAAH) attenuates naloxone-precipitated opioid withdrawal signs in mice via activation of $\mathrm{CB}$, receptors. Complete FAAH inhibition blocks only a subset of withdrawal signs, whereas complete MAGL inhibition elicits enhanced antiwithdrawal efficacy, but is accompanied with some cannabimimetic side effects. Thus, the primary objective of the present study was to determine whether combined, full FAAH inhibition and partial MAGL represents an optimal strategy to reduce opioid withdrawal. To test this hypothesis, we examined whether combined administration of high-dose of the FAAH inhibitor PF-3845 and low-dose of the MAGL inhibitor JZLI 84, as well as the novel dual FAAHMAGL inhibitor SA-57, which is 100 -fold more potent in inhibiting FAAH than MAGL, would prevent spontaneous withdrawal in morphine-dependent mice, a model with greater face validity than precipitating withdrawal with $\mu$-opioid receptor antagonists. Strikingly, a combination of low-dose JZLI84 and high-dose PF-3845 as well as the dual inhibitor SA-57 reduced all abrupt withdrawal signs (ie, platform jumping, paw flutters, head shakes, diarrhea, and total body weight loss), but did not elicit any cannabimimetic side effects. In addition, JZLI 84 or PF-3845 blocked naloxone-precipitated hypersecretion in morphine-dependent small intestinal tissue. Collectively, these results are the first to show that endocannabinoid catabolic enzyme inhibitors reduce abrupt withdrawal in morpine-dependent mice and are effective in a novel in vitro model of opioid withdrawal. More generally, these findings support the idea that joint MAGL and FAAH inhibition represents a promising approach for the treatment of opioid dependence.

Neuropsychopharmacology (2013) 38, 1039-1049; doi:10.1038/npp.2012.269; published online 6 February 2013
\end{abstract}

Keywords: anandamide; 2-AG; fatty acid amide hydrolase (FAAH); monoacylglycerol lipase (MAGL); morphine withdrawal; endocannabinoid

\section{INTRODUCTION}

Dependence to illicit and prescription opioids represents a debilitating disease and serious public health problem (Blanco et al, 2007). Although conventional medications for opioid dependence, such as methadone or buprenorphine prevent withdrawal symptoms in opiate-dependent individuals, these compounds possess dependence liability and can also trigger withdrawal upon abrupt discontinuation (Dyer et al, 1999; Kuhlman et al, 1998). Consequently, a need remains for the development of non-opioid drug therapies that lack dependence and abuse liability. A case

\footnotetext{
*Correspondence: Dr AH Lichtman, Department of Pharmacology and Toxicology, Virginia Commonwealth University, PO Box 980613, Richmond, VA 23298-06/3, USA, Tel: + 804828 8480, Fax: + I8048282117, E-mail: alichtma@vcu.edu

Received 7 October 2012 ; revised 26 December 2012; accepted 28 December 2012; accepted article preview online 3 January 2013
}

report from the nineteenth century in which a tincture of cannabis was prescribed to treat an opium addict (Birch, 1889) signified the first hint of recorded evidence, suggesting the use of cannabinoids to treat opiate dependence. A recent study consistent with this idea reported an association between intermittent cannabis use and improved retention in naltrexone treatment amongst opiate-dependent patients (Raby et al, 2009). The most benefit appeared to occur during the first 30 days of detoxification and induction onto naltrexone, when dropout was steepest. Similarly, preclinical studies have firmly established that the primary active constituent of cannabis delta-9-tetrahydrocannabinol (THC) effectively reduces the intensity of withdrawal signs in opiate-dependent rodents (Bhargava, 1976; Hine et al, 1975). However, psychomimetic effects and dependence liability of THC dampens enthusiasm for its use to treat opiate-dependent patients.

Conversely, the endogenous cannabinoid (endocannabinoid) system, consisting of $\mathrm{CB}_{1}$ and $\mathrm{CB}_{2}$ receptors (Matsuda 
et al, 1993; Munro et al, 1993), the endogenous ligands, anandamide (AEA) and 2-arachidonylglycerol (2-AG) (Devane et al, 1992; Mechoulam et al, 1995; Sugiura et al, 2002), and endocannabinoid biosynthetic and catabolic enzymes (Ahn et al, 2008), possesses potential therapeutic targets to treat opiate dependence and other conditions. Many studies have demonstrated that elevating AEA and 2AG through pharmacological inhibition of their respective primary degradative enzymes,such as fatty acid amide hydrolase (FAAH) (Cravatt et al, 1996, 2001) and monoacylglycerol lipase (MAGL) (Dinh et al, 2002) decreases nociceptive behavior in multiple preclinical models of pain (Ahn et al, 2009; Cravatt et al, 2001; Ghosh et al, 2012; Kinsey et al, 2009; Long et al, 2009a; Schlosburg et al, 2010), anxiety (Kathuria et al, 2003; Patel and Hillard, 2006; Kinsey et al, 2011; Sciolino et al, 2011), and drug dependence (Ramesh et al, 2011; Schlosburg et al, 2009). In particular, high doses of the MAGL inhibitor JZL184 reduces all measured naloxone-precipitated somatic withdrawal signs in morphine-dependent mice, including jumps, paw flutters, weight loss, and diarrhea (Ramesh et al, 2011). However, JZL184 also elicits some cannabimimetic side effects, such as hypomotility and hyperreflexia (Long et al, 2009a), and repeated administration of high-dose JZL184 results in cannabinoid dependence and functional $\mathrm{CB}_{1}$ receptor tolerance (Schlosburg et al, 2010). Although repeated administration of low doses of JZL184 elicit antinociceptive and anxiolytic-like effects that do not lead to tolerance (Busquets-Garcia et al, 2011; Sciolino et al, 2011), low dose JZL184 was only partially effective in reducing opioid withdrawal responses (Ramesh et al, 2011). On the other hand, high doses of FAAH inhibitors do not elicit cannabimimetic side effects and sustained pharmacological inhibition of FAAH does not lead to $\mathrm{CB}_{1}$ receptor functional tolerance or cannabinoid dependence (Falenski et al, 2010; Schlosburg et al, 2010). However, inhibition of this enzyme prevents only a subset of withdrawal responses in morphine-dependent mice (Ramesh et al, 2011). Therefore, the primary objective of the present study was to determine whether dual inhibition of FAAH and MAGL would reduce withdrawal signs in morphine-dependent mice, with minimal cannabimimetic side effects.

Here, we tested the efficacy of a novel combination of low-dose of the MAGL inhibitor JZL184 and high-dose of the FAAH inhibitor PF-3845 as well as the novel dual inhibitor SA-57, which is $\sim 100$-fold more potent in inhibiting FAAH than MAGL (Niphakis et al, 2012), in reducing abrupt morphine-withdrawal signs. In addition, endocannabinoid levels were quantified in whole brain. Rimonabant was used to infer whether $C_{1}$ receptors mediated the antiwithdrawal effects elicited by dual blockade of MAGL and FAAH. In these studies, we employed a spontaneous withdrawal model because it possesses greater face validity than naloxone-precipitated withdrawal and somatic withdrawal signs persist for an extended duration of time $(8 \mathrm{~h})$, allowing time course assessment. Specific withdrawal signs examined were platform jumping, paw flutters, head shakes, diarrhea, and weight loss.

A secondary goal of this study was to elucidate the mechanism by which endocannabinoid catabolic enzyme inhibitors reduce diarrhea, a common untoward symptom of opioid withdrawal. The antecedents for diarrhea include increases in both motility and secretion of fluids and electrolytes. As we previously determined that FAAH and MAGL inhibitors reduce naloxone-precipitated contractions in morphine-treated mouse ilea (Ramesh et al, 2011), efforts in the present study focused on secretion. Accordingly, we developed an in vitro model of intestinal ion transport that incorporated Ussing chambers to test whether JZL184 and PF-3845 differentially inhibit naloxone-precipitated hypersecretion of electrolytes in morphine-treated small intestinal tissue.

\section{MATERIALS AND METHODS}

\section{Subjects}

Male ICR mice (Harlan laboratories; Indianapolis) weighing between 26 and $30 \mathrm{~g}$ ( $\sim 5$ weeks of age) served as subjects. For the in vitro Ussing chambers studies, female C57BL/6J mice (4-6 weeks old; Jackson laboratories, Bar Harbor, ME) and female $\mathrm{CB}_{1}(-/-)$ and their $(+/+)$ littermates backcrossed onto a C57BL/6J background for at least 14 generations were used as subjects. The mice were housed 45 per cage in a temperature controlled $\left(20-22^{\circ} \mathrm{C}\right)$ vivarium approved by the American Association for the Accreditation of Laboratory Animal Care. The mice were maintained on a 12-h light/dark cycle, with all experiments performed during the light cycle. Food and water were available ad libitum. The study was performed with the approval of the Institutional Animal Care and Use Committee at Virginia Commonwealth University and University of Maryland at Baltimore in accordance with the Guide for the Care and Use of Laboratory Animals.

\section{Drugs}

Morphine pellets (75 mg), placebo pellets, morphine sulfate, THC, and rimonabant were obtained from the National Institute on Drug Abuse (Bethesda, MD). Naloxone hydrochloride was purchased from Cayman chemicals (Ann Arbor, MI). JZL184 and PF-3845 were synthesized as described previously and supplied by Organix (Woburn, MA) (Ahn et al, 2009; Long et al, 2009a). SA-57 was synthesized in the laboratory of Dr Cravatt as previously described (Niphakis et al, 2012). THC, PF-3845, JZL184, SA57 , and rimonabant were dissolved in ethanol, followed by addition of Alkamuls-620 (Sanofi-Aventis, Bridgewater, NJ), and diluted with $0.9 \%$ saline to form a vehicle mixture of ethanol, Alkamuls-620, and saline in a ratio of $1: 1: 18$. Doses were calculated by weight of the salt. Naloxone and morphine were dissolved in $0.9 \%$ saline. All injections were administered in volume of $0.01 \mathrm{ml}$ per $1 \mathrm{~g}$ body weight. THC and naloxone were administered via subcutaneous injection, whereas PF-3845, JZL184, SA-57 and rimonabant were given via intraperitoneal (i.p.) injection. In spontaneous withdrawal studies, all injections were given $1 \mathrm{~h}$ after pellet removal. For experiments quantifying brain endocannabinoid levels, JZL184, PF-3845, and SA-57 were administered $2 \mathrm{~h}$ before decapitation. In studies employing the Ussing chambers, naloxone and morphine were dissolved in Krebs buffer, and JZL184 and PF-3845 were dissolved in DMSO. 


\section{Spontaneous Morphine Withdrawal}

Approximately $72 \mathrm{~h}$ after morphine pellet implantation (see Supplementary methods), mice were weighed and behavior was observed. Mice were individually housed overnight prior to the test day. The mice were then given light isoflurane anesthesia, the pellets were surgically extracted, and the mice were returned to their cages that were placed on heating pads for $2 \mathrm{~h}$. At $1 \mathrm{~h}$ after pellet removal, groups received an injection of drug or vehicle. The animals were observed for spontaneous withdrawal signs for 15-min intervals at 2, 4, 6, and 8-h post-pellet removal. Spontaneous withdrawal signs were quantified using a procedure adapted from (Way et al, 1969) that included the percentage of mice jumping off a circular platform $(12-\mathrm{cm}$ diameter $\times 70-\mathrm{cm}$ height), the total number of paw flutter and head shake incidences, and body weights recorded at each time point. Paw flutters and head shakes were, respectively, pooled across all time points to represent the total number of incidences of the behaviors observed. The percentage of mice presenting with diarrhea across the 8-h test session was also recorded. The mice remained singly housed throughout the testing period, and food and water were available ad libitum, except during the 15-min observation periods. We also measured naloxone-precipitated opioid withdrawal in mice treated with a combination of MAGL and FAAH inhibitors (see Supplementary methods).

For methods of behavioral assessment of cannabinoid activity, extraction, and quantification of brain endocannabinoid levels, and in vitro measure of secretion in small intestine (ie, measurement of electrogenic ion transport in vitro in Ussing chambers), see Supplementary information.

\section{Statistical Analysis}

All data are reported as mean \pm SEM. In the behavioral experiments, the numbers of head shake and paw tremor incidences were tallied. The occurrence of jumps and diarrhea was scored as a binary event for the entire 15min period at each time point. Weight loss (g) was calculated by subtracting the body weight at the conclusion of each 15-min observation period from the pre-pellet removal weight. Data were analyzed using one-way or twoway between measures analysis of variance. Dunnett's test was to compare drug treatments with vehicle and Scheffe's post-hoc test was employed for comparisons between various treatments. In addition, planned comparisons were used to analyze the brain levels of endocannabinoids. The percentage of mice between groups presenting with diarrhea and percentage of mice that jumped off platforms were analyzed by the $z$-test of two proportions. For Ussing chambers experiments, planned comparisons using $t$-tests were performed between different treatments. Differences were considered statistically significant at $p<0.05$.

\section{RESULTS}

\section{MAGL and FAAH Inhibition Differentially Attenuates Spontaneous Morphine-Withdrawal Signs}

Consistent with previous reports (Long et al, 2009a, b), JZL184 dose-dependently elevated whole-brain levels of 2$\operatorname{AG}(\mathrm{F}(3,19)=19.5 ; p<0.001$; Figure 1a) and concomitantly reduced levels of arachidonic acid $(\mathrm{F}(3,19)=8.4 ; p<0.001$; Figure 1b), but did not relevantly affect AEA levels (Figure 1c). In addition, JZL184 dose-relatedly reduced all
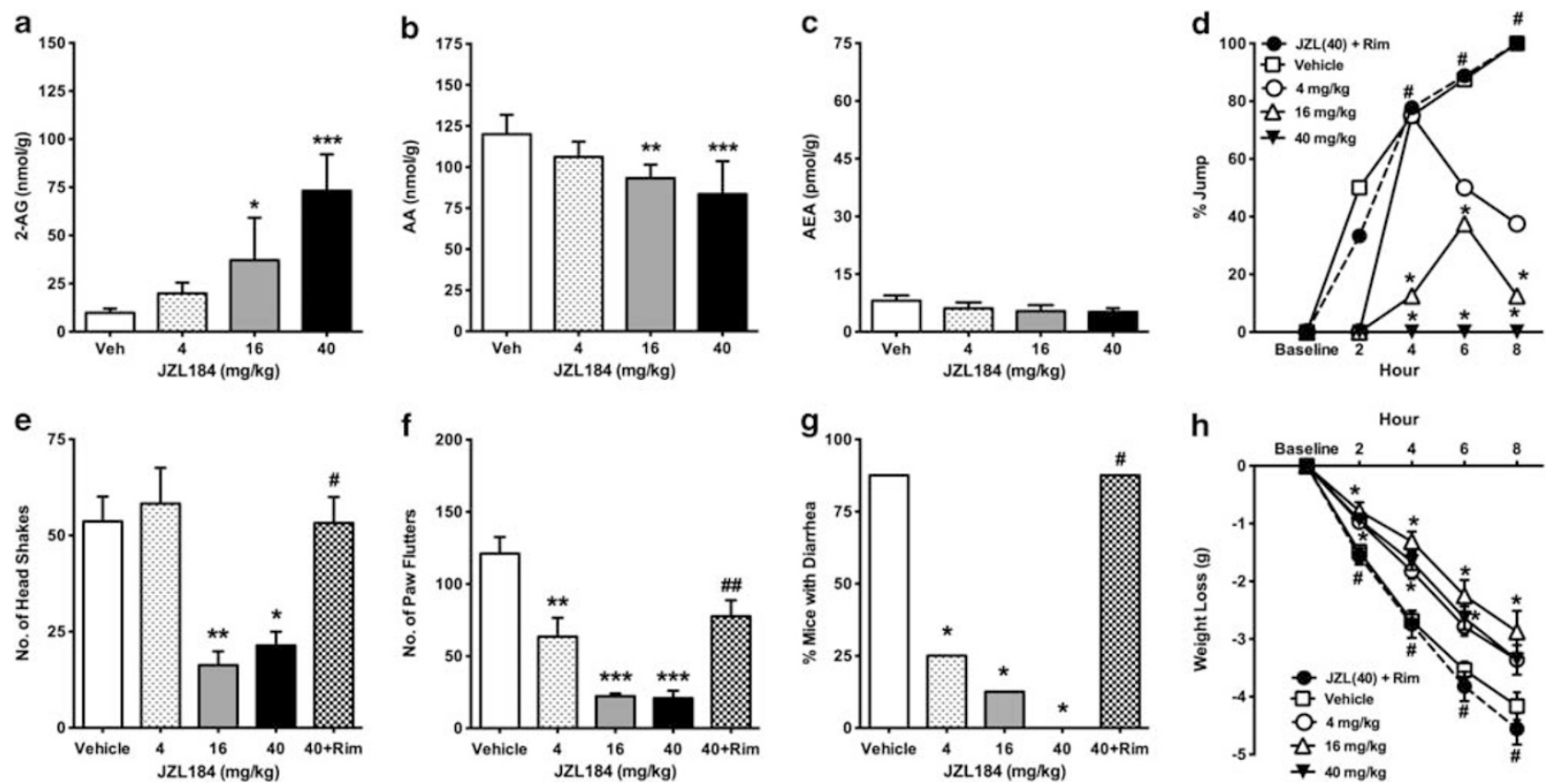

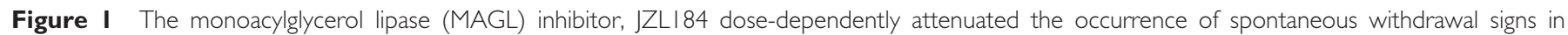

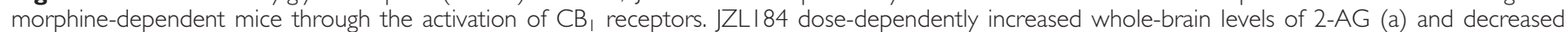

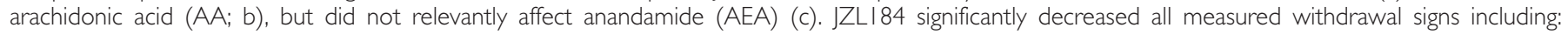

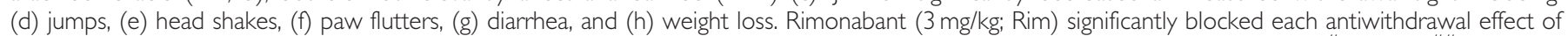

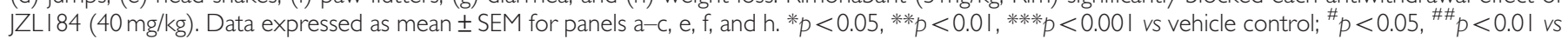
JZL I84(40)-treated group; $n=7-9$ mice/group. 
measured spontaneous withdrawal signs in morphinedependent mice, including the percentage of mice jumping from the platform (Figure 1d), total number of head shakes $(\mathrm{F}(3,28)=12.1 ; p<0.001$; Figure 1e), paw flutters $(\mathrm{F}(3,28)=26.4 ; p<0.001$; Figure 1f), the occurrence of diarrhea (Figure 1g), and weight loss across all time points $(\mathrm{F}(12,112)=4.0 ; p<0.001$; Figure $1 \mathrm{~h})$. Rimonabant reversed all antiwithdrawal actions of JZL184 (40 mg/kg), including jumps (Figure 1d), number of total head shakes $(\mathrm{F}(2,22)=9.7 ; \quad p<0.001 ;$ Figure $1 \mathrm{e})$, and paw flutters $(\mathrm{F}(2,22)=24.8 ; p<0.001$; Figure 1f), diarrhea (Figure 1g), and weight loss $(\mathrm{F}(8,84)=5.3 ; p<0.001$; Figure $1 \mathrm{~h})$.

Similarly, the phytocannabinoid THC blocked all measured withdrawal signs, including the occurrence of jumping (Figure 2a), head shakes $(\mathrm{F}(2,19)=13.5$; $p<0.001$; Figure 2b), paw flutters $(\mathrm{F}(2,19)=59.6$; $p<0.001$; Figure 2c), diarrhea (Figure 2d), and weight loss $(\mathrm{F}(4,52)=4.0 ; p<0.01$; Figure $2 \mathrm{e})$ in morphine-dependent mice, undergoing spontaneous withdrawal. In comparison, the FAAH inhibitor PF-3845 (10 mg/kg, i.p.) administered to morphine-dependent mice undergoing spontaneous morphine withdrawal significantly attenuated a subset of withdrawal signs, including head shakes, paw flutters, and jumping behavior at the 6-h time point, only (Figure 2a-c). However, PF-3845 did not affect the incidence of diarrhea (Figure 2d) or weight loss (Figure 2e).

\section{Combination of Partial MAGL Inhibition and Complete FAAH Inhibition Attenuates Spontaneous and Precipitated Withdrawal Signs through Activation of $\mathrm{CB}_{1}$ Receptors}

To evaluate whether combined inhibition of MAGL and FAAH reduces spontaneous opioid withdrawal signs, mice were co-administered a low dose of JZL184 (4 mg/kg, i.p.) or vehicle and a high dose of PF-3845 (10 mg/kg, i.p.) or vehicle. Acute treatment with low-dose JZL184 given with vehicle or in combination with high-dose PF-3845 significantly elevated 2-AG levels two- to four-fold ( $\mathrm{F}(3$, $28)=25.7 ; p<0.001$; Figure 3a). PF-3845 given alone did not alter brain 2-AG levels. The combination of JZL184 and PF3845 resulted in significantly higher 2-AG brain levels than those produced by JZL184 (4 mg/kg) alone, though this elevation did not approach the 10 -fold increased levels following high-dose JZL184 (40 mg/kg), which is comparable to its effectiveness in C57BL/6J mice (Long et al, 2009b). High-dose JZL184 (40 mg/kg) decreased brain arachidonic acid levels by $47 \% \quad(76.9 \pm 3.8 \mathrm{nmol} / \mathrm{g}$; $p<0.001)$. Similarly, low-dose JZL184 (4 mg/kg) significantly reduced brain arachidonic acid levels when administered alone or in combination with PF-3845, $(\mathrm{F}(3,28)=4.6$; $p<0.05$; Figure $3 \mathrm{~b}$ ); however, the respective reductions were only 11 and $15 \%$, compared with vehicle control levels. As shown in Figure 3c, PF-3845 or combination of PF-3845 + JZL184, increased brain AEA levels more than eight-fold above that of vehicle $(\mathrm{F}(3,28)=309 ; p<0.001)$. However, neither 4 nor $40 \mathrm{mg} / \mathrm{kg}$ JZL184 given alone affected AEA levels in whole brain.

Strikingly, JZL184 (4 mg/kg) and PF-3845 (10 mg/kg) given in combination reduced the full spectrum of abrupt withdrawal signs, while single administration of these drugs reduced only a subset of withdrawal signs. The combination of JZL184 and PF-3845, but neither drug alone, significantly reduced jumping at 4,6 , and $8 \mathrm{~h}$ after morphine pellet removal (Figure $3 \mathrm{~d}$ ). The combination as well as each drug given alone significantly reduced the intensity of total head shakes $(\mathrm{F}(3,26)=4.4 ; p<0.01$; Figure $3 \mathrm{e})$ and paw flutters $(\mathrm{F}(3,26)=12.3 ; p<0.001$; Figure $3 \mathrm{f})$. However, only the combination of JZL184 and PF-3845 significantly blocked the occurrence of diarrhea (Figure $3 \mathrm{~g}$ ) and ameliorated the
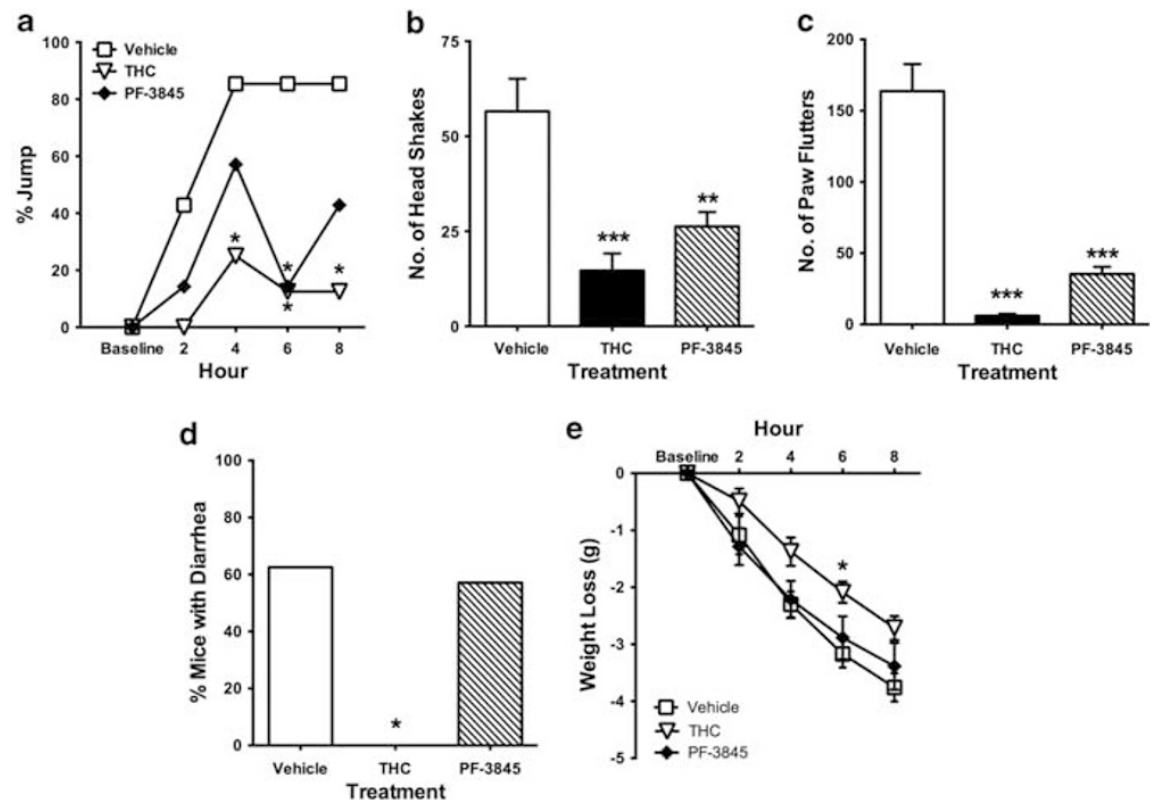

Figure 2 The phytocannabinoid, tetrahydrocannabinol (THC) completely blocked all measured spontaneous withdrawal signs in morphine-dependent mice, while the FAAH inhibitor, PF-3845 attenuated only a subset of the withdrawal signs. The withdrawal signs measured include: (a) jumps, (b) head shakes, (c) paw flutters, (d) diarrhea, and (e) weight loss. Data are expressed as mean \pm SEM for panels b-d, and percentage scores for panels a and e. * $p<0.05$ vs morphine control; $n=7-8$ mice/group. 

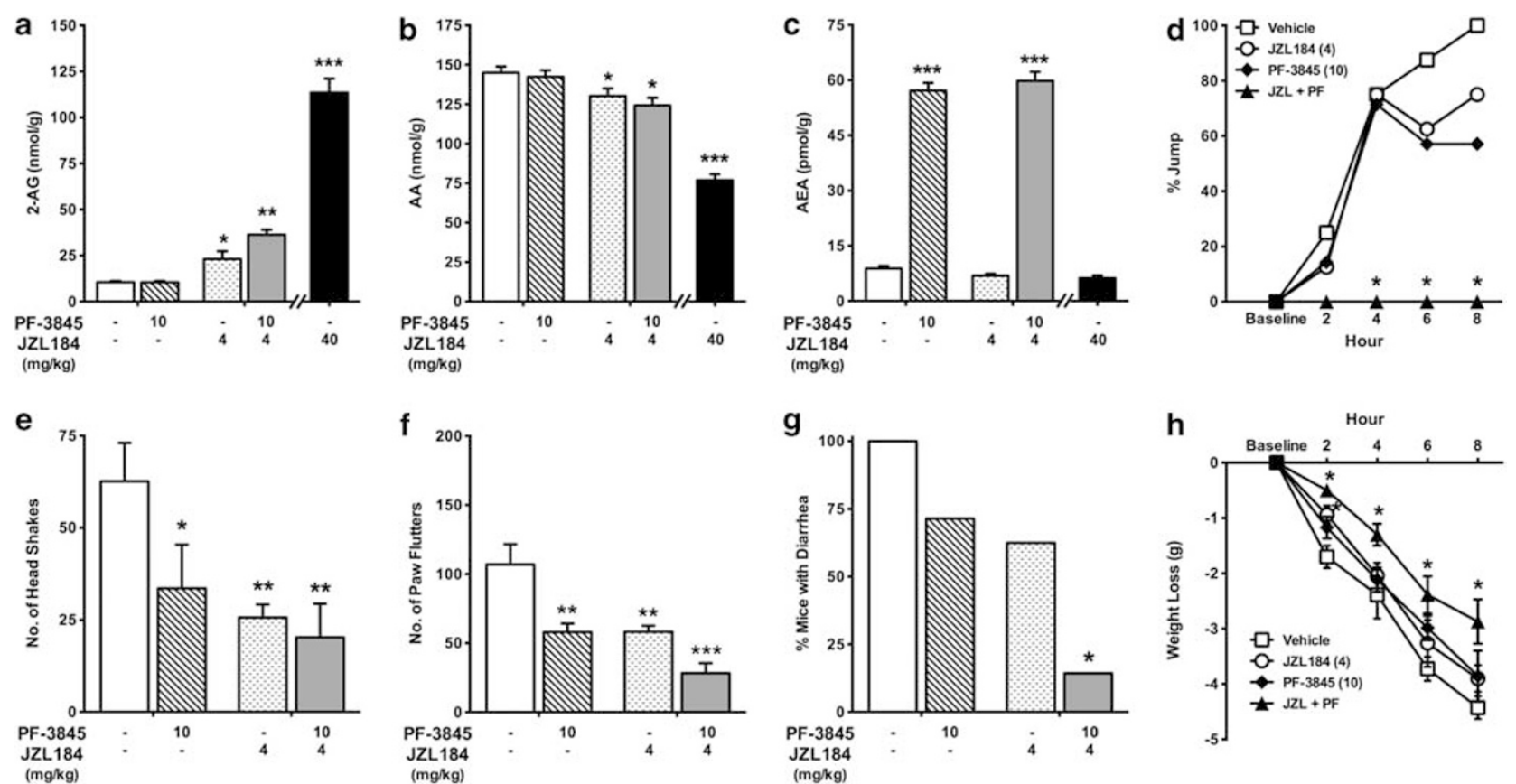

Figure 3 Combined administration of a threshold dose of IZLI84 (4 mg/kg) and high dose of PF-3845 (I $0 \mathrm{mg} / \mathrm{kg}$; IZL + PF) attenuated the occurrence of the spontaneous withdrawal signs in morphine-dependent mice to a greater extent than either inhibitor alone. The effects of vehicle or low-dose JZLI84 $(4 \mathrm{mg} / \mathrm{kg})$ combined with vehicle or high-dose PF-3845 (10 mg/kg) on whole-brain levels of (a) 2-AG, (b) arachidonic acid (AA), and (c) AEA. The effects of high-dose JZLI $84(40 \mathrm{mg} / \mathrm{kg}$ ) are included for comparison. The withdrawal signs measured include: (d) jumps, (e) head shakes, (f) paw flutters, (g) diarrhea, and $(h)$ weight loss. Data expressed as mean \pm SEM for panels a-c and $-f-h$. $* p<0.05$, *** $<<0.01$, **** $p<0.00$ I vs morphine control; $n=7-8$ mice/group.
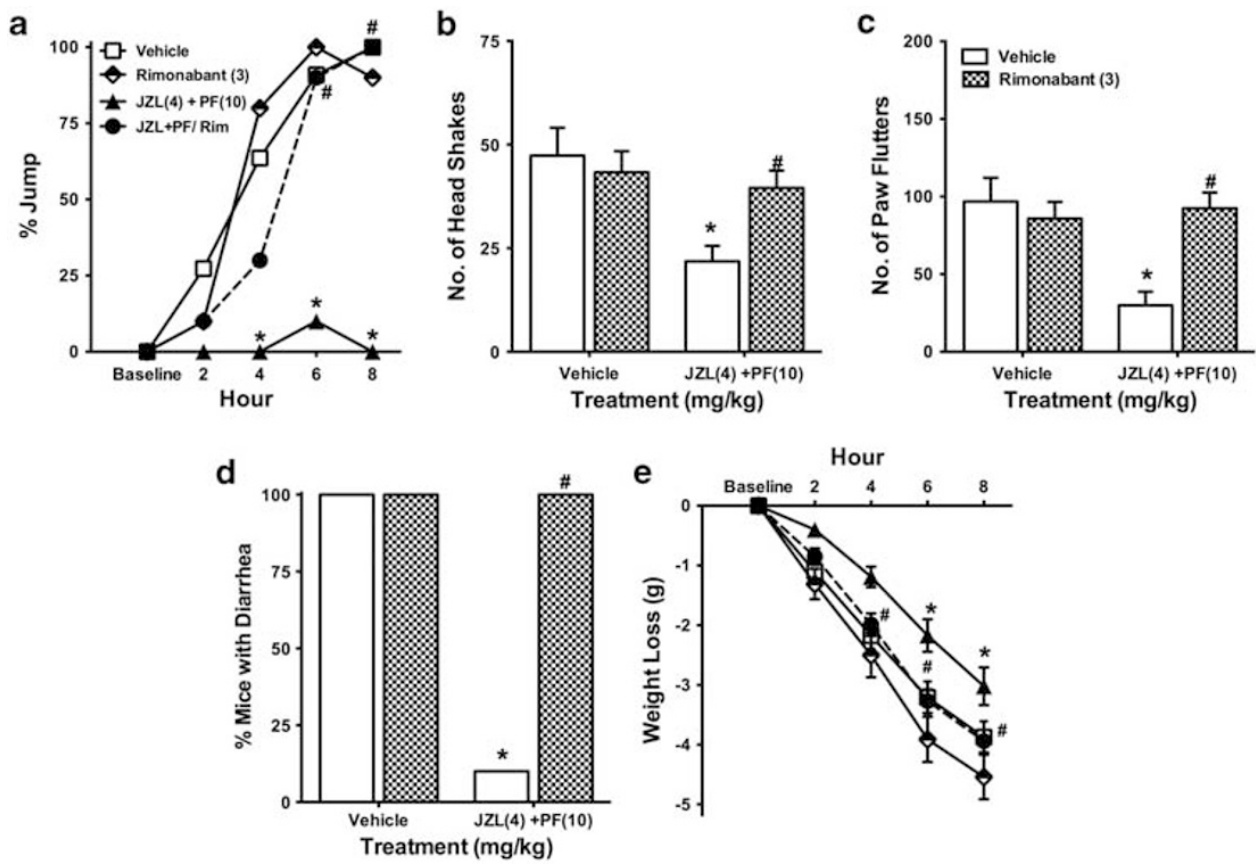

Figure $4 \quad \mathrm{CB}_{\text {| }}$ receptors mediate the antiwithdrawal effects of combined administration of a threshold dose of JZLI84 (4 mg/kg) and a high dose of PF-3845 (I0 mg/kg; (JZL + PF)) in morphine-dependent mice. All subjects were implanted with morphine pellets for $72 \mathrm{~h}$. One hour after pellet removal to elicit spontaneous withdrawal, subjects received the following two injections: (I) rimonabant ( $3 \mathrm{mg} / \mathrm{kg}$; Rim) or vehicle, and (2) JZL + PF or vehicle. The withdrawal signs measured include: (a) Jumps, (b) head shakes, (c) paw flutters, (d) diarrhea, and (e) weight loss. Data are expressed as mean \pm SEM for panels b, c and e. ${ }^{*} p<0.05$, vs vehicle control, ${ }^{\#} p<0.05$ vs JZL + PF condition; $n=10-11$ mice/group.

intensity of weight loss $(\mathrm{F}(3,26)=4.8 ; p<0.01$; Figure $3 \mathrm{~h})$. Rimonabant completely prevented all antiwithdrawal effects of combined administration of JZL184 and PF-3845 in morphine-dependent mice following pellet removal, includ- ing the occurrence of jumps (Figure $4 \mathrm{a})$, head shakes $(\mathrm{F}(1$, $37)=4.4 ; p<0.05$; Figure $4 \mathrm{~b})$, paw flutters $(\mathrm{F}(1,37)=9.9$; $p<0.01$; Figure $4 \mathrm{c}$ ), diarrhea (Figure $4 \mathrm{~d}$ ), and weight loss $(\mathrm{F}(12,108)=2.8 ; p<0.01$; Figure $4 \mathrm{e})$. 
Combination of JZL184 (4 mg/kg) and PF-3845 (10 mg/ $\mathrm{kg}$ ) also significantly blocked the occurrence of withdrawal signs in the naloxone-precipitated withdrawal model of dependence. As can be seen in Figure 5, combined administration of JZL184 and PF-3845 reduced the frequency of jumping $(\mathrm{F}(3,26)=4.6 ; p<0.01$; Panel a), paw flutter incidents $(\mathrm{F}(3,26)=5.6 ; p<0.01$; Panel b), diarrhea (Panel c), and weight loss $(\mathrm{F}(3,26)=8.9 ; p<0.001$; Panel d).

To determine the efficacy of a dual FAAH and MAGL inhibitor on morphine-dependent mice undergoing spontaneous withdrawal, we employed SA-57, which is greater than 100 -fold more potent as a FAAH inhibitor than as a MAGL inhibitor (Niphakis et al, 2012). As shown in Figure $6 \mathrm{a}, 0.125$ and $1.25 \mathrm{mg} / \mathrm{kg}$ SA-57 did not alter brain 2 -AG levels, but $2.5,5$, and $12.5 \mathrm{mg} / \mathrm{kg} \mathrm{SA}-57$ significantly elevated brain 2-AG levels, respectively, by three- to fourfold, seven-fold, and greater than ten-fold $(\mathrm{F}(5,24)=305.5$; $p<0.0001)$. High doses of SA-57 were also required to reduce brain arachidonic acid levels (Figure 6b). Specifically, 5 and $12.5 \mathrm{mg} / \mathrm{kg}$ SA-57 significantly reduced brain arachidonic acid levels by 33 and $60 \%$, respectively, $(\mathrm{F}(5$, $24)=10.9 ; p<0.0001)$. In contrast, SA-57 was considerably more potent in elevating brain AEA levels than 2-AG levels, with $0.125 \mathrm{mg} / \mathrm{kg}$ increasing AEA approximately three-fold and each of the higher doses producing maximally elevated brain AEA levels $(F(5,24)=49.0 ; p<0.0001$; Figure $6 c)$.

Having confirmed that SA-57 is far more potent in elevating brain levels of AEA than 2-AG in ICR mice, we next evaluated whether this compound would reduce spontaneous withdrawal signs in morphine-dependent mice. SA-57 dose-dependently reduced the occurrence of
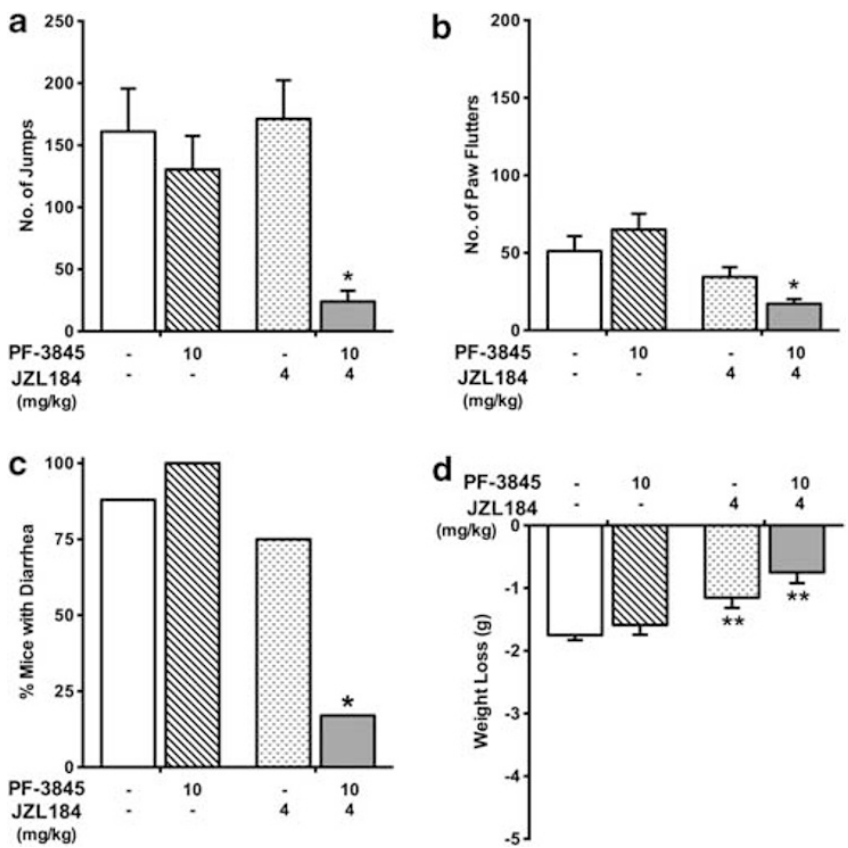

Figure 5 Combined administration of low dose JZL $84(4 \mathrm{mg} / \mathrm{kg})$ and high-dose PF-3845 (10 mg/ $/ \mathrm{kg})$ attenuated the occurrence of the naloxoneprecipitated withdrawal signs in morphine-dependent mice to a greater extent than either inhibitor alone. The withdrawal signs measured include: (a) jumps, (b) paw flutters, (c) diarrhea as well as (d) weight loss. Data expressed as mean \pm SEM for panels $a, b$ and $d$. $* p<0.05$, $* * * 0.01$ vs morphine control; $n=6-8$ mice/group. platform jumping (Figure 6d), the total number of head shakes $(\mathrm{F}(3,32)=4.34 ; p<0.05$; Figure $6 \mathrm{e})$ and paw flutters $(\mathrm{F}(3,32)=18.0 ; p<0.0001$; Figure $6 \mathrm{f})$. This compound also attenuated the occurrence of diarrhea (Figure $6 \mathrm{~g}$ ) and weight loss at all time points $(\mathrm{F}(3,32)=5.99 ; p<0.01$; Figure $6 \mathrm{~h}$ ), but only at the $5 \mathrm{mg} / \mathrm{kg}$ dose in each case.

\section{Combined Partial MAGL and Full FAAH Inhibition: Lack of Discernible Cannabimimetic Side Effects in the Tetrad Assay}

To evaluate whether dual blockade of MAGL and FAAH elicits cannabimimetic effects, we assessed combined injections of JZL184 and PF-3845 in the tetrad assay, which is sensitive to the pharmacological actions of THC and other cannabinoid receptor agonists. Mice treated with low-dose JZL184 $(4 \mathrm{mg} / \mathrm{kg})$, PF-3845 $(10 \mathrm{mg} / \mathrm{kg})$, or combination of both inhibitors displayed no significant effects in the tetrad assay (Table 1). In comparison, THC dose-dependently elicited hypomotility, anti-nociception, hypothermia, and catalepsy (Supplementary Table 1). As shown in Table 2, SA-57 produced significant increases in hypomotility $(\mathrm{F}(4$, $34)=3.18 ; p<0.05)$, catalepsy $(\mathrm{F}(4,35)=3.61 ; p<0.05)$, and hypothermia $(\mathrm{F}(4,35)=20.8 ; p<0.0001)$, but not antinociception $(p=0.37)$. Each of these effects can be attributed to the highest dose tested (ie, $12.5 \mathrm{mg} / \mathrm{kg}$ SA-57; $p<0.05$ ), are comparable to those elicited by high doses of THC (Supplementary Table 1), and are consistent with previous studies (Long et al, 2009c) showing that complete and simultaneous inhibition of MAGL and FAAH elicits almost full-blown cannabimimetic effects.

Comparison between JZL184 and PF-3845 on NaloxonePrecipitated Hypersecretion in Morphine-Treated Small Intestinal Tissue

In the final experiment, we developed an in vitro model to examine whether endocannabinoid catabolic enzyme inhibitors reduce naloxone-precipitated secretion in morphine-treated small intestine. Morphine treatment by itself caused a mild decrease in the $\mathrm{I}_{\mathrm{sc}}$ current, consistent with its constipation side effect. Naloxone $(30 \mu \mathrm{M})$ application to SI tissue treated with morphine $(30 \mu \mathrm{M})$ for $60 \mathrm{~min}$, produced a profound increase in $\mathrm{I}_{\mathrm{sc}}$ current $(p<0.05 \mathrm{v} / \mathrm{s}$ morphine control; Figure 7). JZL184 $(10 \mu \mathrm{M})$ or PF-3845 $(1 \mu \mathrm{M})$ blocked naloxone-induced increase in $\mathrm{I}_{\mathrm{sc}}$ current in wildtype tissue $(p<0.05 \mathrm{v} / \mathrm{s}$ morphine-naloxone control; Figure 7a and c). However, JZL184 lacked this antisecretory action in tissue from $\mathrm{CB}_{1}(-/-)$ mice (Figure $\left.7 \mathrm{~b}\right)$.

\section{DISCUSSION}

The major finding of the present study is that partially blocking MAGL in combination with full FAAH blockade substantially reduced spontaneous withdrawal signs in morphine-dependent mice compared with single inhibition of these endocannabinoid catabolic enzymes. Specifically, combined administration of low dose of the MAGL inhibitor JZL184 (ie, $4 \mathrm{mg} / \mathrm{kg}$ ) and high dose of the FAAH inhibitor PF-3845 (ie, $10 \mathrm{mg} / \mathrm{kg}$ ) significantly reduced paw flutters, head shakes, jumps, diarrhea, and weight loss in morphine-dependent mice undergoing spontaneous or 

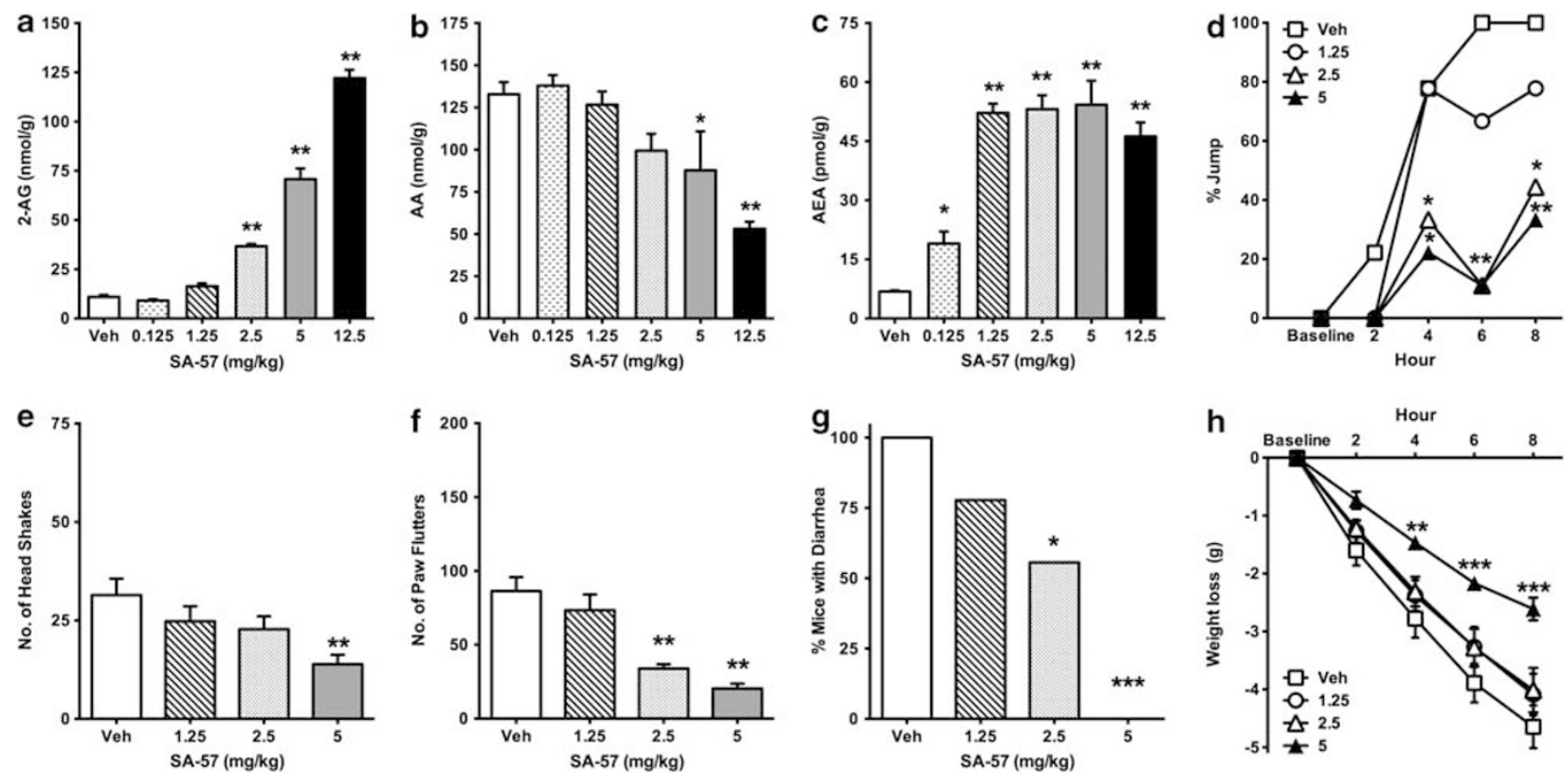

Figure 6 The dual FAAH/MAGL inhibitor SA-57 reduced all measured signs of spontaneous morphine withdrawal. SA-57 dose-dependently increased whole-brain levels of 2-AG (a) and concomitantly increased arachidonic acid (AA; b), but was most potent in elevating brain AEA levels (c). The withdrawal signs measured include: (d) jumps, (e) head shakes, ( $f$ ) paw flutters, (g) diarrhea, and (h) weight loss. Data are expressed as mean \pm SEM for panels a-c and e, $f$, and $h$, and percentage scores in panels $d$ and $h$. ${ }^{p} p<0.05$, *** $p<0.01$, ${ }^{*} * * * 0.001$ vs morphine control; $n=9$ mice/group.

Table I Tetrad Effects of JZLI84 vs Vehicle given in Combination with PF-3845 or Vehicle

\begin{tabular}{lccrc}
\hline Treatment $(\mathbf{m g} / \mathbf{k g})$ & Hypothermia $\left(\boldsymbol{\Delta}^{\circ} \mathbf{C}\right)$ & Tail withdrawal latency $(\boldsymbol{\Delta s})$ & Catalepsy (s) & Time immobile $(\mathbf{s})$ \\
\hline Vehicle & $0.46 \pm 0.3$ & $-0.23 \pm 0.2$ & 0.00 & $11.2 \pm 1.5$ \\
JZLI84 (4) & $0.19 \pm 0.3$ & $0.01 \pm 0.1$ & 0.00 & $9.7 \pm 2.9$ \\
PF-3845 (I0) & $0.18 \pm 0.2$ & $0.10 \pm 0.2$ & 0.00 & $10.7 \pm 1.8$ \\
JZLI84 (4)+PF-3845 (I0) & $0.31 \pm 0.2$ & $-0.26 \pm 0.2$ & 0.00 & $19.1 \pm 7.0$
\end{tabular}

Time immobile (s) for activity, catalepsy time (s) was assessed in the bar test, tail withdrawal latency (s) was assessed in the warm water tail withdrawal test, and change in rectal temperature $\left({ }^{\circ} \mathrm{C}\right)$ for hypothermia. See Supplementary Table I for comparison of THC in these four measures. Values represent mean \pm SEM, $n=7-9$ ICR mice per group.

Table 2 Assessment of Cannabimimetic Effects of the Dual MAGL-FAAH Inhibitor SA-57 in ICR Mice

\begin{tabular}{lcccc}
\hline SA-57 $(\mathbf{m g} / \mathbf{k g})$ & Hypothermia $(\boldsymbol{\Delta} \mathbf{C})$ & Tail withdrawal latency $(\boldsymbol{\Delta} \mathbf{s})$ & Catalepsy $(\mathbf{s})$ & Time immobile $(\mathbf{s})$ \\
\hline Vehicle & $-0.18 \pm 0.2$ & $0.25 \pm 0.35$ & 0.00 & $13.9 \pm 1.2$ \\
1.25 & $-0.17 \pm 0.4$ & $0.69 \pm 0.3$ & 0.00 & $16.1 \pm 6.2$ \\
2.5 & $-0.21 \pm 0.2$ & $0.72 \pm 0.4$ & 0.00 & $15.4 \pm 3.2$ \\
5 & $-0.3 \pm 0.15$ & $0.20 \pm 0.2$ & 0.00 & $25.3 \pm 16.8$ \\
12.5 & $-3.41 \pm 0.5 * * *$ & $0.43 \pm 0.6$ & $4.86 \pm 2.6 *$ & $68.5 \pm 21.9 *$ \\
\hline
\end{tabular}

Abbreviations: FAAH, fatty acid amide hydrolase; MAGL, monoacylglycerol lipase.

Time immobile (s) for activity, catalepsy time (s) was assessed in the bar test, tail withdrawal latency (s) was assessed in the warm water tail withdrawal test, and change in rectal temperature $\left({ }^{\circ} \mathrm{C}\right)$ for hypothermia. See Supplementary Table I for comparison of THC in these four measures. Values represent mean \pm SEM, $n=7-9$ ICR mice per group. ${ }^{*} p<0.05$, ${ }^{*} * * * 0.00$ I vs vehicle control.

naloxone-precipitated withdrawal. Rimonabant blocked the antiwithdrawal effects of the combination of JZL184 and PF3845 , indicating that $\mathrm{CB}_{1}$ receptors have a necessary role in mediating these antiwithdrawal actions. Likewise, the dual
FAAH-MAGL inhibitor, SA-57 significantly blocked all spontaneous withdrawal signs in morphine-dependent mice. Importantly, combined blockade of MAGL and FAAH resulted in increased brain levels of endocannabinoids, but 

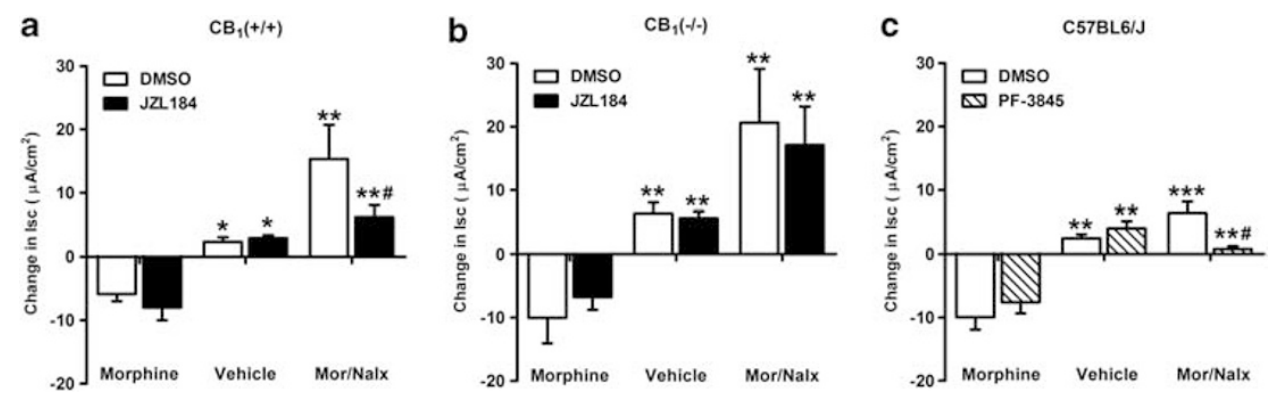

Figure 7 Effects of MAGL inhibition on naloxone-precipitated hypersecretion in $\mathrm{CB}_{1}(+/+)$ and $\mathrm{CB}_{1}(-/-)$ mice. (a) JZLI84 blocked naloxoneprecipitated hypersecretion in morphine-treated small intestine tissue from $\mathrm{CB}_{1}(+/+)$ mice, did not alter naloxone-precipitated hypersecretion in tissue from $\mathrm{CB}_{1}(-/-)$ mice (b). Finally, PF-3845 blocked naloxone-precipitated hypersecretion in morphine-treated small intestine tissue from C57/BL6

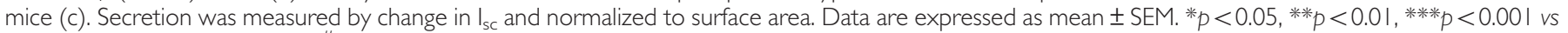
appropriate morphine control; ${ }^{\#} p<0.05$ vs corresponding morphine-naloxone treated tissue; $n=4-5$ mice/group.

did not produce apparent cannabimimetic effects (except for $12.5 \mathrm{mg} / \mathrm{kg} \mathrm{SA}-57$ ), as assessed in the tetrad assay. A second novel finding in the present study was that both JZL184 and PF-3845 significantly attenuated naloxoneprecipitated hypersecretion in morphine-dependent intestinal tissue.

The findings that high-dose JZL184 significantly blocked all opioid withdrawal symptoms, whereas high-dose PF3845 reduced only a subset of these effects corroborate a previous report using the naloxone-precipitated withdrawal model (Ramesh et al, 2011). However, the partial cannabimimetic effects produced by high-dose JZL184 (Long et al, 2009a) could represent a drawback in developing MAGL inhibitors as stand-alone therapeutic agents for opioid dependence. Although FAAH inhibitors do not elicit observable cannabimimetic side effects, PF-3845 was less efficacious than JZL184 in reducing spontaneous (see Figures 1 and 2) and naloxone-precipitated (Ramesh et al, 2011) opioid withdrawal signs. Taken together, these results suggest that FAAH and MAGL represent promising targets for treating opioid dependence and other disorders. However, selective inhibitors of these enzymes are associated with respective challenges related to efficacy and side effects. Moreover, complete blockade of MAGL and FAAH in combination has been shown to produce enhanced antinociceptive effects, as well as THC-like subjective effects in the drug discrimination assay, catalepsy, hypomotility, and impaired performance in a working memory Morris water maze memory task (Long et al, 2009c; Wise et al, 2012). In order to circumvent these limitations, we investigated whether a combination of partial MAGL inhibition and complete FAAH inhibition would achieve enhanced efficacy in attenuating opioid withdrawal signs without assorted THC-like side effects elicited by simultaneous and complete blockade of both these major endocannabinoid catabolic enzymes (Long et al, 2009c). It is somewhat curious that none of the treatments significantly elevated tail withdrawal latencies, though we previously reported (Cravatt et al, 2001) that FAAH $(-/-)$ mice do not exhibit hypoalgesic responses at the water temperature use here (ie, $52^{\circ} \mathrm{C}$ ). The antiwithdrawal effects of this combination coupled with the lack of cannabimimetic effects are important findings, supporting further development of a drug that partially inhibits MAGL, and completely inhibits FAAH. Notably, the dual inhibitor
SA-57, which much more potently inhibits FAAH than MAGL (Niphakis et al, 2012), elicited differential potency in elevating brain AEA and 2-AG levels and dose-dependently attenuated spontaneous withdrawal in morphine-dependent mice.

Although FAAH and MAGL are well established to be the primary hydrolytic enzymes of AEA and 2-AG, both of which activate $\mathrm{CB}_{1}$ and $\mathrm{CB}_{2}$ receptors, non-endocannabinoid substrates of these enzymes and their receptor targets are also affected by inhibitors of these enzymes (Ahn et al, 2008). In particular, MAGL has a major role in the biosynthesis of free arachidonic acid in brain from its precursor, 2-AG (Nomura et al, 2011). Also, FAAH metabolizes other bioactive fatty acid amides, including $\mathrm{N}$-palmitoylethanolamine, $\mathrm{N}$-oleoylethanolamine, and oleamide (Cravatt et al, 1996, 2001), as well as $N$-acyl taurines (Fattore et al, 2005; Leung et al, 2006), which activate various TRP channels and PPAR $\alpha$ receptors (Di Marzo and De Petrocellis, 2010; Jhaveri et al, 2008; Smart et al, 2000). Thus, combined blockade of FAAH and MAGL produces multiple neurochemical alterations that could affect morphine-withdrawal responses. Nonetheless, the observation that rimonabant completely prevented all antiwithdrawal effects produced by combined administration of JZL184 and PF-3845 in morphine-dependent mice indicates that endocannabinoid activation of $\mathrm{CB}_{1}$ receptors has a necessary role in these actions. Similarly, rimonabant, but not the $\mathrm{CB}_{2}$ receptor antagonist SR144528, prevented the protective effects of JZL184 on naloxone-precipitated withdrawal signs in morphine-dependent mice (Ramesh et al, 2011).

Although compelling evidence supports the idea that AEA and 2-AG have pivotal roles in mediating the enhanced antiwithdrawal effects elicited by dual inhibition of their primary catabolic enzymes, the manner by which these two endocannabinoids interact, remains to be established. A simple explanation is that dual enzyme inhibition produces enhanced antiwithdrawal effects by merely increasing total endocannabinoid brain levels to stimulate $\mathrm{CB}_{1}$ receptors. However, the observation that 2-AG levels in brain are at least 200-fold higher than AEA brain levels (Ahn et al, 2009; Long et al, 2009a) tends to argue against this idea of mass action. Alternatively, it is plausible that simultaneous inhibition of MAGL and FAAH may produce augmented antiwithdrawal effects because distinct $\mathrm{CB}_{1}$ receptor-mediated circuits are activated by the respective 
endocannabinoids. Consistent with this idea is that FAAH is predominantly expressed on post-synaptic terminals (Gulyas et al, 2004) and MAGL is expressed on presynaptic terminals (Dinh et al, 2002). Also, as discussed above, other consequences of enzyme inhibition may further contribute to the antiwithdrawal effects (eg, decreased brain levels of arachidonic acid or increased brain levels of non-cannabinoid fatty acid amides).

A secondary objective of the present study was to elucidate the mechanistic basis of the differential antidiarrheal effects between JZL184 and PF-3845 during morphine withdrawal. Antecedents for diarrhea include enhanced contractility and increased secretion of fluids and electrolytes. As JZL184 and PF-3845 were each previously found to attenuate naloxoneprecipitated contraction of morphine-dependent ileum (Ramesh et al, 2011), we reasoned that secretion in the ileum may account for the differential antidiarrheal effects between these enzyme inhibitors. Accordingly, we developed an in vitro model of naloxone-precipitated secretion in morphine-dependent small intestine tissue using Ussing chambers to test this hypothesis. As previously reported (Sheldon et al, 1990), morphine alone reduced electrolyte and fluid transport. In contrast, naloxone challenge to morphine-exposed small intestine elicited profound increases in $\mathrm{I}_{\mathrm{sc}}$ current in isolated tissue, indicating hypersecretion. However, the observations that both JZL184 and PF-3845 prevented this response suggest that secretion alone may not mechanistically account for the differential antidiarrheal actions of these endocannabinoid catabolic enzyme inhibitors. Alternatively, this in vitro assay of naloxoneprecipitated secretion in morphine-exposed tissue may not model the underlying changes mediating the occurrence of diarrhea in animals undergoing opioid withdrawal. Nonetheless, this study introduces a novel and viable in vitro assay of opiate withdrawal in which Ussing chambers can be used to quantify hypersecretory responses precipitated by naloxone in morphine-exposed small intestine.

Although the results of the present study highlight the potential of the endocannabinoid catabolic enzyme inhibitors to treat opioid withdrawal, it will be important to assess this strategy on other components of opioid addiction, including drug seeking behavior, self-administration, extinction, and reinstatement. As the $\mathrm{CB}_{1}$ receptor antagonist rimonabant attenuates heroin self-administration (Navarro et al, 2001) and reinstatement of heroin self-administration (Fattore et al, 2005), whereas full $\mathrm{CB}_{1}$ receptor agonists such as CP55,940 and WIN55,212-2 restores heroin self-administration (Fattore et al, 2003) in rats, it will be important to determine the degree to which elevating endocannabinoids may affect resumption of drug taking behavior. Furthermore, although somatic withdrawal signs represent an important component of opioid withdrawal, it remains to be established whether manipulations of the endocannabinoid system also attenuate affective opioid withdrawal signs (Frenois et al, 2002), which are thought to contribute to the 'dark side of drug addiction' (Koob and Le Moal, 2005). Experiments examining the efficacy of these compounds to reduce conditioned place avoidance behavior associated with opioid withdrawal or decreased responding for intracranial self-stimulation caused by opioid withdrawal will provide further insight into these important aspects of dependence.
The in vitro and in vivo data presented here establish that endocannabinoid catabolic enzymes represent attractive targets to treat severe withdrawal signs associated with opioid dependence. The novel combination of partial MAGL inhibition coupled with complete FAAH inhibition produces increased levels of endocannabinoid in brain, elicits no discernible cannabimimetic side effects, and blocks the wide spectrum of somatic opiate withdrawal signs through a $\mathrm{CB}_{1}$ receptor mechanism of action in mice. This study is the first comprehensive evaluation of the effects of THC, as well as endocannabinoid catabolic enzyme inhibitors on spontaneous opioid withdrawal. In addition, we have established a novel end-point for opioid withdrawal in vitro using Ussing chambers to measure effects of withdrawal induced changes in intestinal secretion. Specifically, prolonged morphine exposure led to adaptations in the electrogenic mucosal ion transport as evidenced by the hypersecretory response induced by acute naloxone challenge. In addition, inhibitors of endocannabinoid catabolic enzymes blunt the naloxone-precipitated withdrawal response. Thus, dual inhibition of FAAH and MAGL offers a promising strategy to treat opioid dependence.

\section{ACKNOWLEDGEMENTS}

We thank Scott T. O’Neal, Shu Yan, Carlotta Jackson and Kelly Long for their technical assistance. This research was supported by R01DA032933 (BFC \& AHL), P01DA009789 (AHL), P01DA017259 (BFC), P50DA005274 (AHL), T32DA007027 (TFG), RO1AI49316 (TS-D); TV is supported by a research grant of the Flanders Research Foundation (Fonds Wetenschappelijk Onderzoek, FWO Belgium). This research has been entirely supported by the NIH.

\section{DISCLOSURE}

The authors declare no conflict of interest. Drs Cravatt and Lichtman serve on the advisory board of Abide Therapeutics. Dr Lichtman also serves as a consultant for Ironwood Pharmaceuticals.

\section{REFERENCES}

Ahn K, Johnson DS, Mileni M, Beidler D, Long JZ, McKinney MK et al (2009). Discovery and characterization of a highly selective FAAH inhibitor that reduces inflammatory pain. Chem Biol 16: 411-420.

Ahn K, McKinney MK, Cravatt BF (2008). Enzymatic pathways that regulate endocannabinoid signaling in the nervous system. Chem Rev 108: 1687-1707.

Bhargava HN (1976). Effect of some cannabinoids on naloxoneprecipitated abstinence in morphine-dependent mice. Psychopharmacology 49: 267-270.

Birch EA (1889). The use of Indian hemp in the treatment of chronic chloral and chronic opium poisoning. The Lancet 133: 625.

Blanco C, Alderson D, Ogburn E, Grant BF, Nunes EV, Hatzenbuehler ML et al (2007). Changes in the prevalence of non-medical prescription drug use and drug use disorders in the United States: 1991-1992 and 2001-2002. Drug Alcohol Depend 90: $252-260$

Busquets-Garcia A, Puighermanal E, Pastor A, de la Torre R, Maldonado R, Ozaita A (2011). Differential role of anandamide 
and 2-arachidonoylglycerol in memory and anxiety-like responses. Biol Psychiatry 70: 479-486.

Cravatt BF, Demarest K, Patricelli MP, Bracey MH, Giang DK, Martin BR et al (2001). Supersensitivity to anandamide and enhanced endogenous cannabinoid signaling in mice lacking fatty acid amide hydrolase. Proc Natl Acad Sci USA 98: 9371-9376.

Cravatt BF, Giang DK, Mayfield SP, Boger DL, Lerner RA, Gilula NB (1996). Molecular characterization of an enzyme that degrades neuromodulatory fatty-acid amides. Nature 384: 83-87.

Devane WA, Hanus L, Breuer A, Pertwee RG, Stevenson LA, Griffin $\mathrm{G}$ et al (1992). Isolation and structure of a brain constituent that binds to the cannabinoid receptor. Science 258: 1946-1949.

Di Marzo V, De Petrocellis L (2010). Endocannabinoids as regulators of transient receptor potential (TRP) channels: a further opportunity to develop new endocannabinoid-based therapeutic drugs. Curr Med Chem 17: 1430-1449.

Dinh TP, Carpenter D, Leslie FM, Freund TF, Katona I, Sensi SL et al (2002). Brain monoglyceride lipase participating in endocannabinoid inactivation. Proc Natl Acad Sci USA 99: 10819-10824.

Dyer KR, Foster DJ, White JM, Somogyi AA, Menelaou A, Bochner F (1999). Steady-state pharmacokinetics and pharmacodynamics in methadone maintenance patients: comparison of those who do and do not experience withdrawal and concentration-effect relationships. Clin Pharmacol Ther 65: 685-694.

Falenski KW, Thorpe AJ, Schlosburg JE, Cravatt BF, Abdullah RA, Smith TH et al (2010). FAAH - / - mice display differential tolerance, dependence, and cannabinoid receptor adaptation after delta 9-tetrahydrocannabinol and anandamide administration. Neuropsychopharmacology 35: 1775-1787.

Fattore L, Spano MS, Cossu G, Deiana S, Fratta W (2003). Cannabinoid mechanism in reinstatement of heroin-seeking after a long period of abstinence in rats. Eur J Neurosci 17: 1723-1726.

Fattore L, Spano S, Cossu G, Deiana S, Fadda P, Fratta W (2005). Cannabinoid CB(1) antagonist SR 141716A attenuates reinstatement of heroin self-administration in heroin-abstinent rats. Neuropharmacology 48: 1097-1104.

Frenois F, Cador M, Caille S, Stinus L, Le Moine C (2002). Neural correlates of the motivational and somatic components of naloxone-precipitated morphine withdrawal. Eur J Neurosci 16: 1377-1389.

Ghosh S, Wise LE, Chen Y, Gujjar R, Mahadevan A, Cravatt BF et al (2012). The monoacylglycerol lipase inhibitor JZL184 suppresses inflammatory pain in the mouse carrageenan model. Life Sciences.

Gulyas AI, Cravatt BF, Bracey MH, Dinh TP, Piomelli D, Boscia F et al (2004). Segregation of two endocannabinoid-hydrolyzing enzymes into pre- and postsynaptic compartments in the rat hippocampus, cerebellum and amygdala. Eur J Neurosci 20: 441-458.

Hine B, Friedman E, Torrelio M, Gershon S (1975). Morphinedependent rats: blockade of precipitated abstinence by tetrahydrocannabinol. Science 187: 443-445.

Jhaveri MD, Richardson D, Robinson I, Garle MJ, Patel A, Sun Y et al (2008). Inhibition of fatty acid amide hydrolase and cyclooxygenase-2 increases levels of endocannabinoid related molecules and produces analgesia via peroxisome proliferatoractivated receptor-alpha in a model of inflammatory pain. Neuropharmacology 55: 85-93.

Kathuria S, Gaetani S, Fegley D, Valino F, Duranti A, Tontini A et al (2003). Modulation of anxiety through blockade of anandamide hydrolysis. Nat Med 9: 76-81.

Kinsey SG, Long JZ, O’Neal ST, Abdullah RA, Poklis JL, Boger DL et al (2009). Blockade of endocannabinoid-degrading enzymes attenuates neuropathic pain. J Pharmacol Exp Ther 330: 902-910.

Kinsey SG, O’Neal ST, Long JZ, Cravatt BF, Lichtman AH (2011). Inhibition of endocannabinoid catabolic enzymes elicits anxio- lytic-like effects in the marble burying assay. Pharmacol Biochem Behav 98: 21-27.

Koob GF, Le Moal M (2005). Plasticity of reward neurocircuitry and the 'dark side' of drug addiction. Nat Neurosci 8: 1442-1444.

Kuhlman JJ Jr, Levine B, Johnson RE, Fudala PJ, Cone EJ (1998). Relationship of plasma buprenorphine and norbuprenorphine to withdrawal symptoms during dose induction, maintenance and withdrawal from sublingual buprenorphine. Addiction 93: 549-559.

Leung D, Saghatelian A, Simon GM, Cravatt BF (2006). Inactivation of $\mathrm{N}$-acyl phosphatidylethanolamine phospholipase $\mathrm{D}$ reveals multiple mechanisms for the biosynthesis of endocannabinoids. Biochemistry 45: 4720-4726.

Long JZ, Li W, Booker L, Burston JJ, Kinsey SG, Schlosburg JE et al (2009a). Selective blockade of 2-arachidonoylglycerol hydrolysis produces cannabinoid behavioral effects. Nat Chem Biol 5: 37-44.

Long JZ, Nomura DK, Cravatt BF (2009b). Characterization of monoacylglycerol lipase inhibition reveals differences in central and peripheral endocannabinoid metabolism. Chem Biol 16: 744-753.

Long JZ, Nomura DK, Vann RE, Walentiny DM, Booker L, Jin X et al (2009c). Dual blockade of FAAH and MAGL identifies behavioral processes regulated by endocannabinoid crosstalk in vivo. Proc Natl Acad Sci USA 106: 20270-20275.

Matsuda LA, Bonner TI, Lolait SJ (1993). Localization of cannabinoid receptor mRNA in rat brain. J Comp Neurol 327: 535-550.

Mechoulam R, Ben-Shabat S, Hanus L, Ligumsky M, Kaminski N, Schatz A et al (1995). Identification of an endogenous 2monoglyceride, present in canine gut, that binds to cannabinoid receptors. Biochem Pharmacol 50: 83-90.

Munro S, Thomas KL, Abu-Shaar M (1993). Molecular characterization of a peripheral receptor for cannabinoids. Nature 365: 61-65.

Navarro M, Carrera MR, Fratta W, Valverde O, Cossu G, Fattore L et al (2001). Functional interaction between opioid and cannabinoid receptors in drug self-administration. J Neurosci 21: $5344-5350$.

Niphakis MJ, Johnson DS, Ballard TE, Stiff C, Cravatt BF (2012). O-hydroxyacetamide carbamates as a highly potent and selective class of endocannabinoid hydrolase inhibitors. ACS Chem Neurosci 3: 418-426.

Nomura DK, Morrison BE, Blankman JL, Long JZ, Kinsey SG, Marcondes MC et al (2011). Endocannabinoid hydrolysis generates brain prostaglandins that promote neuroinflammation. Science 334: 809-813.

Patel S, Hillard CJ (2006). Pharmacological evaluation of cannabinoid receptor ligands in a mouse model of anxiety: further evidence for an anxiolytic role for endogenous cannabinoid signaling. J Pharmacol Exp Ther 318: 304-311.

Raby WN, Carpenter KM, Rothenberg J, Brooks AC, Jiang H, Sullivan M et al (2009). Intermittent marijuana use is associated with improved retention in naltrexone treatment for opiatedependence. Am J Addict 18: 301-308.

Ramesh D, Ross GR, Schlosburg JE, Owens RA, Abdullah RA, Kinsey SG et al (2011). Blockade of endocannabinoid hydrolytic enzymes attenuates precipitated opioid withdrawal symptoms in mice. J Pharmacol Exp Ther 339: 173-185.

Schlosburg JE, Blankman JL, Long JZ, Nomura DK, Pan B, Kinsey SG et al (2010). Chronic monoacylglycerol lipase blockade causes functional antagonism of the endocannabinoid system. Nat Neurosci 13: 1113-1119.

Schlosburg JE, Carlson BL, Ramesh D, Abdullah RA, Long JZ, Cravatt BF et al (2009). Inhibitors of endocannabinoidmetabolizing enzymes reduce precipitated withdrawal responses in THC-dependent mice. AAPS J 11: 342-352. 
Sciolino NR, Zhou W, Hohmann AG (2011). Enhancement of endocannabinoid signaling with JZL184, an inhibitor of the 2 -arachidonoylglycerol hydrolyzing enzyme monoacylglycerol lipase, produces anxiolytic effects under conditions of high environmental aversiveness in rats. Pharmacol Res 64: 226-234.

Sheldon RJ, Riviere PJ, Malarchik ME, Moseberg HI, Burks TF, Porreca F (1990). Opioid regulation of mucosal ion transport in the mouse isolated jejunum. J Pharmacol Exp Ther 253: 144-151.

Smart D, Gunthorpe MJ, Jerman JC, Nasir S, Gray J, Muir AI et al (2000). The endogenous lipid anandamide is a full agonist at the human vanilloid receptor (hVR1). Br J Pharmacol 129: 227-230.
Sugiura T, Kobayashi Y, Oka S, Waku K (2002). Biosynthesis and degradation of anandamide and 2-arachidonoylglycerol and their possible physiological significance. Prostaglandins Leukot Essent Fatty Acids 66: 173-192.

Way EL, Loh HH, Shen FH (1969). Simultaneous quantitative assessment of morphine tolerance and physical dependence. J Pharmacol Exp Ther 167: 1-8.

Wise LE, Long KA, Abdulla RA, Long JZ, Cravatt BF, Lichtman AH (2012). Dual fatty acid amide hydrolase and monoacylglycerol lipase blockade produces THC-like Morris water maze deficits in mice. ACS Chem Neurosci 217: 485-494.

Supplementary Information accompanies the paper on the Neuropsychopharmacology website (http://www.nature.com/npp) 